\title{
MAPEAMENTO DE RISCOS A INUNDAÇÃO NA ÁREA URBANA DE PARACATU - MG
}

\author{
Patrícia Soares Rezende ${ }^{(a)}$, Daniela Vieria Marques ${ }^{(b)}$ \\ (a) Insituto de Geografia, Universidade Federal de Uberlândia-UFU, ps.rezende@ hotmail.com \\ (b) Insituto de Geografia, Universidade Federal de Uberlândia-UFU, danivmarx@ gmail.com
}

\section{Eixo: GEOTECNOLOGIAS E MODELAGEM ESPACIAL EM GEOGRAFIA FISICA}

\begin{abstract}
Resumo
Este trabalho tem por objetivo conhecer os riscos de inundação no perímetro urbano de Paracatu-MG, por meio da aplicação da técnica de processo analítico hierárquico (AHP), utilizando software livre. Nos resultados alcançados foi constatado que as áreas de risco alto e muito alto estão localizadas no sul da cidade e apresentam como principais características a urbanização acentuada, baixas declividades e relevo plano, sendo estes alguns dos fatores que contribuem para ocorrência de inundações. Em contrapartida, áreas consideradas como de risco baixo e muito baixo estão distribuídas onde predominam relevo ondulado, áreas permeáveis e vegetação, fatores que contribuem para que não ocorram inundações, garantindo uma qualidade ambiental em áreas urbanas.
\end{abstract}

Palavras chave: Geoprocessamento, risco de inundação; análise multicritério.

\section{Introdução}

O uso de geotecnologias contribui para mostrar quais áreas podem ou não ser ocupadas pela população para fins de moradia, sobretudo em zonas urbanas, destacando quais áreas precisam ser preservadas, daquelas já ocupadas, e quais estão ou não suscetíveis a riscos e qual o grau destes, em particular, os relacionados à inundação. Os mapeamentos e análises realizados a partir de geotecnologias apresentam produtos adequados à realidade e às necessidades locais para uma efetiva tomada de decisão por parte do poder público.

Segundo dados do Censo de 2010 (IBGE, 2014), residem 84,35\% da população brasileira em áreas urbanas. Esse nível de concentração da ocupação urbana se dá, na maioria das cidades, sem um planejamento adequado. Uma das consequências dessa desordem é o constante estado de risco a que a população está exposta, ocupando espaços que, por particularidades naturais como proximidade a encostas de morros e de rios, são inadequados para moradia (MENDONÇA e LEITÃO, 2008).

Partindo da importância dos estudos sobre risco, este trabalho tem como objetivo conhecer os riscos de inundação no perímetro urbano de Paracatu-MG, por meio da aplicação da técnica de processo analítico hierárquico (AHP). 


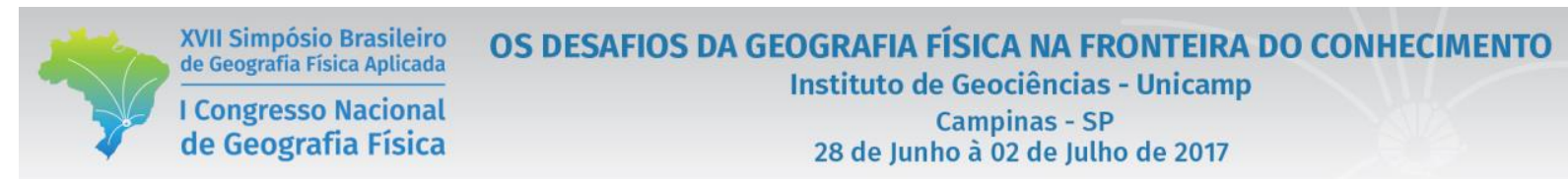

Foi escolhido como objeto de estudo deste trabalho os cursos d'água situados na área urbana do município de Paracatu, em Minas Gerais. A cidade está situada às margens das rodovias BR-040 e MG-188, de acordo com a Figura 1. As áreas não contempladas na análise foram destacadas do restante da área urbana, devido à falta de informação junto aos órgãos oficiais.

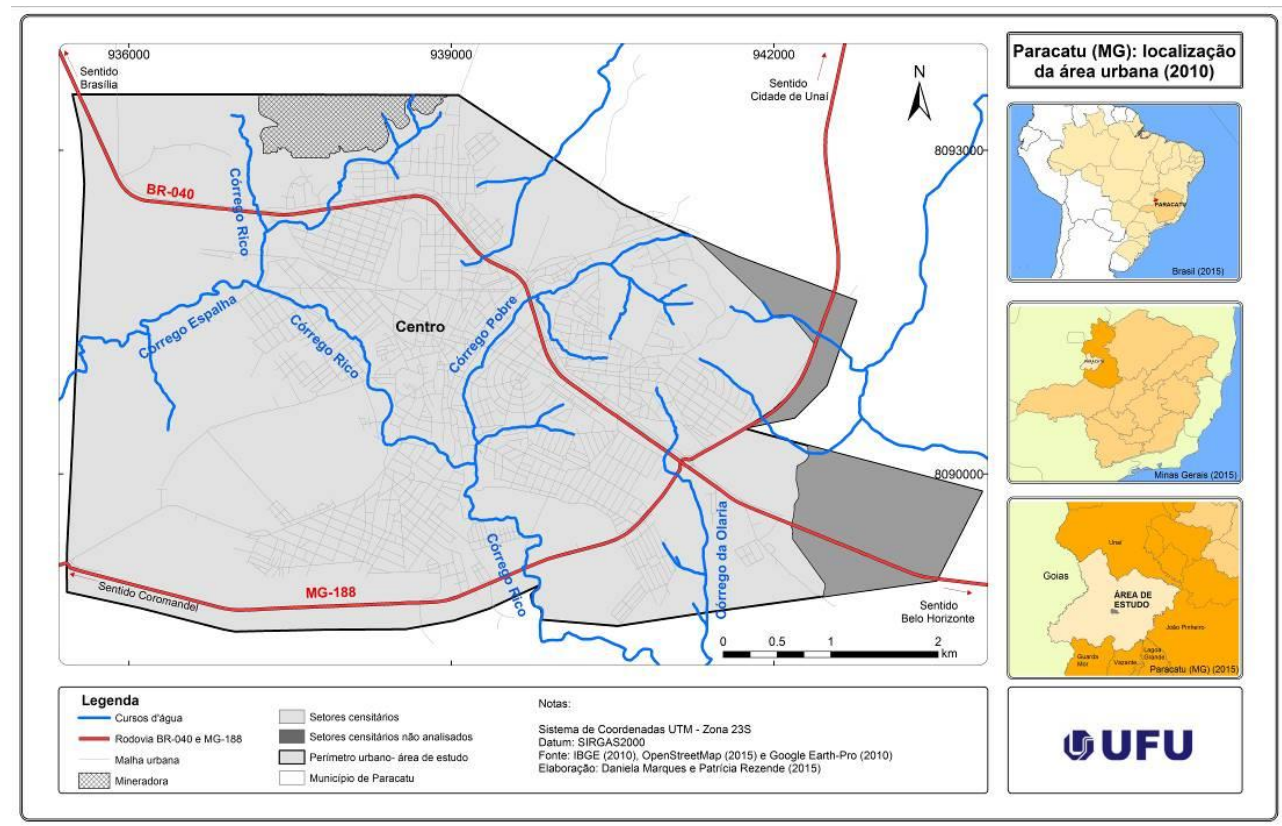

Figura 1 - Localização da área urbana

Segundo dados do Censo Demográfico de 2010 (IBGE, 2014), o município abriga 84.718 habitantes. Do total da população, a grande maioria, cerca de $87 \%$, mora na área urbana e o restante, apenas 10.946 , ainda reside na zona rural.

Dentre as características ambientais da cidade, importantes para o mapeamento de risco à inundação estão a altitude, a declividade e os solos. Tais variáveis ajudam a entender a dinâmica dos processos ambientais na área de estudo quando se observa sua contribuição para a ocorrência ou não de inundação.

\section{Materiais e Métodos}

Os materiais e métodos empregados para este artigo compreendem o uso de imagens do Google EarthPro ${ }^{1}$, SRTM, disponível no site Earth Explorer, administrado pela USGS, de 30 metros e a aplicação do Processo Analítico Hierárquico (Analytic Hierarchy Process) - AHP, método utilizado para identificação das áreas mais sujeitas a riscos de inundação nos cursos d'água da cidade de Paracatu.

${ }^{1}$ É disponibilizado de forma gratuita no site: http://www.google.com/earth/download/gep/agree.html. 


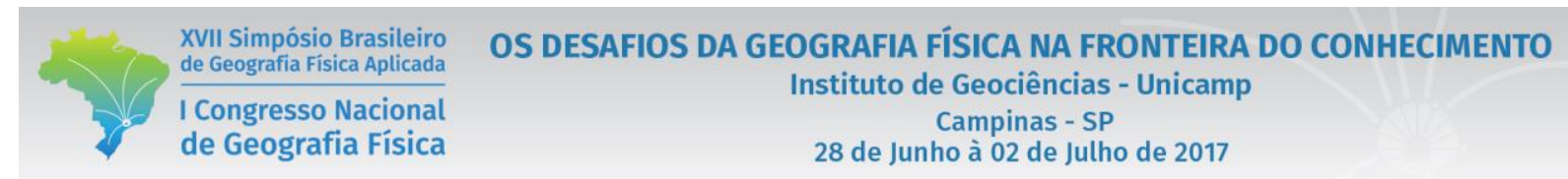

Para aplicação dessa metodologia recorreu-se ao software livre QGis. A preferência por uma ferramenta de código aberto, se deve à necessidade de buscar alternativas para trabalhar dados espaciais em programas livres e de fácil acesso a toda população (QGIS, 2015).

A elaboração do mapa de risco a inundação foi dividida em duas etapas, sendo a primeira destinada a reclassificação das variáveis com atribuição de pesos e posteriormente a aplicação do método AHP.

\section{RECLASSIFICAÇÃO DE VARIÁVEIS}

Nessa etapa fez-se a reclassificação das variáveis em função do seu grau de importância mútua, buscando revelar as áreas mais sujeitas ao risco de inundação na cidade de Paracatu - MG.

Os pesos são estabelecidos a partir de uma escala que varia de 0 a 1, segundo sua importância para o risco de inundação. No caso da cidade de Paracatu, a escala de importância das classes das variáveis foi definida conforme a Tabela 1.

Tabela 1 - Descrição e peso das variáveis utilizadas para mapeamento do risco a inundação

\begin{tabular}{|c|c|c|c|c|c|c|c|c|}
\hline Variáveis & \multicolumn{2}{|c|}{ Solo } & \multicolumn{2}{|c|}{$\begin{array}{c}\text { Uso e ocupação } \\
\text { do solo } \\
\end{array}$} & \multicolumn{2}{|c|}{ Altitude } & \multicolumn{2}{|c|}{ Declividade } \\
\hline 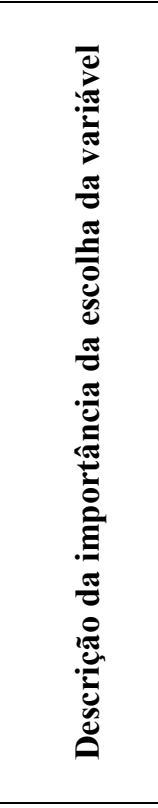 & \multicolumn{2}{|c|}{$\begin{array}{l}\text { A definição dos tipos } \\
\text { de solo existentes na } \\
\text { região de estudo é } \\
\text { necessária, pois cada } \\
\text { um deles possui } \\
\text { diferentes } \\
\text { capacidades de } \\
\text { infiltração e } \\
\text { escoamento } \\
\text { superficial da água } \\
\text { (MAGALHÃES et } \\
\text { al, 2011 e 2012) }\end{array}$} & \multicolumn{2}{|c|}{$\begin{array}{l}\text { Indicador importante, } \\
\text { para demonstrar de que } \\
\text { maneira o espaço foi } \\
\text { ocupado pelo homem e } \\
\text { a interferência nos } \\
\text { mecanismos de } \\
\text { infiltração e } \\
\text { escoamento superficial } \\
\text { da água na terra. De } \\
\text { acordo com Magalhães } \\
\text { et al. "as áreas com } \\
\text { maior } \\
\text { impermeabilidade } \\
\text { tendem a acumular } \\
\text { mais água em } \\
\text { superfície do que em } \\
\text { solos com cobertura } \\
\text { florestal por serem } \\
\text { pouco compactados" } \\
\text { (2011, p. 65) }\end{array}$} & \multicolumn{2}{|c|}{$\begin{array}{l}\text { Essa variável } \\
\text { influencia no risco } \\
\text { a inundação devido } \\
\text { à probabilidade de } \\
\text { inundação em áreas } \\
\text { mais baixas e } \\
\text { também “(...) } \\
\text { devido à ação da lei } \\
\text { da gravidade que } \\
\text { direciona a água } \\
\text { para as regiões mais } \\
\text { baixas" } \\
\text { (MAGALHÃES et } \\
\text { al., 2011, p. 65) }\end{array}$} & \multicolumn{2}{|c|}{$\begin{array}{l}\text { Variável } \\
\text { importante na } \\
\text { determinação dos } \\
\text { riscos de } \\
\text { inundação de uma } \\
\text { área, pois, "(...) } \\
\text { influencia } \\
\text { diretamente no } \\
\text { acúmulo de água } \\
\text { no terreno. Áreas } \\
\text { planas apresentam } \\
\text { maiores } \\
\text { probabilidades de } \\
\text { sofrer inundação } \\
\text { do que áreas } \\
\text { escarpadas" } \\
\text { (MAGALHÃES } \\
\text { et al., 2011, p. 65) }\end{array}$} \\
\hline \multirow{6}{*}{ 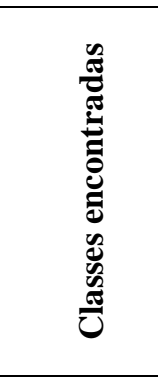 } & Classes & Peso & Classes & Peso & Classes & Peso & Classes & Peso \\
\hline & Neossolo & 1,0 & Lagos & 1,0 & $<685$ & 1,0 & $<2$ & 1,0 \\
\hline & $\begin{array}{c}\text { Associação } \\
\text { Neossolo } \\
\text { Litólico- } \\
\text { Cambissolo } \\
\end{array}$ & 0,5 & $\begin{array}{l}\text { Não- } \\
\text { Edificado }\end{array}$ & 0,6 & $685-715$ & 0,8 & $2-7$ & 0,9 \\
\hline & \multirow{3}{*}{ Latossolo } & \multirow{3}{*}{0,3} & Edificado & 0,3 & $715-745$ & 0,6 & $7-15$ & 0,7 \\
\hline & & & Vegetação & 0,1 & \multirow{2}{*}{$>745$} & \multirow{2}{*}{0,2} & $15-22$ & 0,2 \\
\hline & & & Mineração & 0,1 & & & $>22$ & 0,1 \\
\hline
\end{tabular}




\section{OS DESAFIOS DA GEOGRAFIA FÍSICA NA FRONTEIRA DO CONHECIMENTO \\ Instituto de Geociências - Unicamp \\ Campinas - SP \\ 28 de Junho à 02 de Julho de 2017}

Em relação à definição dos pesos, a literatura sugere que os maiores deles deverão ser atribuídos para as classes com maior risco. Por essa razão, foi definido que as características encontradas nas áreas que apresentam mais susceptibilidade a inundação receberiam notas próximas a 1 e as identificadas em áreas menos susceptíveis, notas menores, sendo avaliada variável por variável, conforme detalhado a seguir:

a) Solos: em decorrência de existirem 3 classes, com graus diferentes de susceptibilidade, optou-se por atribuir a nota mais alta (1) para o solo mais susceptível (Neossolo), nota mediana para o solo oriundo de uma associação entre Neossolo Litólico e Cambissolo (que mescla características de um solo mais susceptível com as de um solo menos susceptível) e, por fim, nota 0,3 para o solo Latossolo, que, em relação aos demais, apresenta menor susceptibilidade à inundação.

b) Uso e ocupação do solo: foi atribuída nota 1 para as áreas com maior possibilidade de inundação (lagos). Para as áreas com maior impermeabilidade (as edificadas), adotou-se uma nota mediana de 0,6, sendo que as menores notas foram para as áreas com risco mínimo de inundação. Apesar da vegetação e mineração terem comportamento diversos, ambas receberam a mesma nota devido área de mineração estar localizada nas maiores altitudes e por ocupar uma pequena faixa do perímetro urbano.

c) Altitude: as notas próximas a 1 dizem respeito às áreas com menores valores de altitude e também localizadas próximas aos cursos d'água, o que influencia o risco de inundação. Já as menores notas referem-se às áreas com maior altitude e mais afastadas dos cursos d'água e, por tais características, menos sujeitas à inundação.

d) Declividade: as notas foram atribuídas levando em consideração o grau de declividade e a proximidade com o curso d'água. Sendo assim, declividades menores receberam notas entre 0,7 e 1, enquanto que as notas 0,2 e 0,1 se referem às maiores declividades, locais com remota possibilidade de inundação.

Os resultados obtidos nessa etapa, observados na Figura 2, são mapas já reclassificados segundo a nota de risco de inundação, levando em consideração os solos (A), o uso e ocupação do solo (B), a altitude (C) e a declividade (D). 


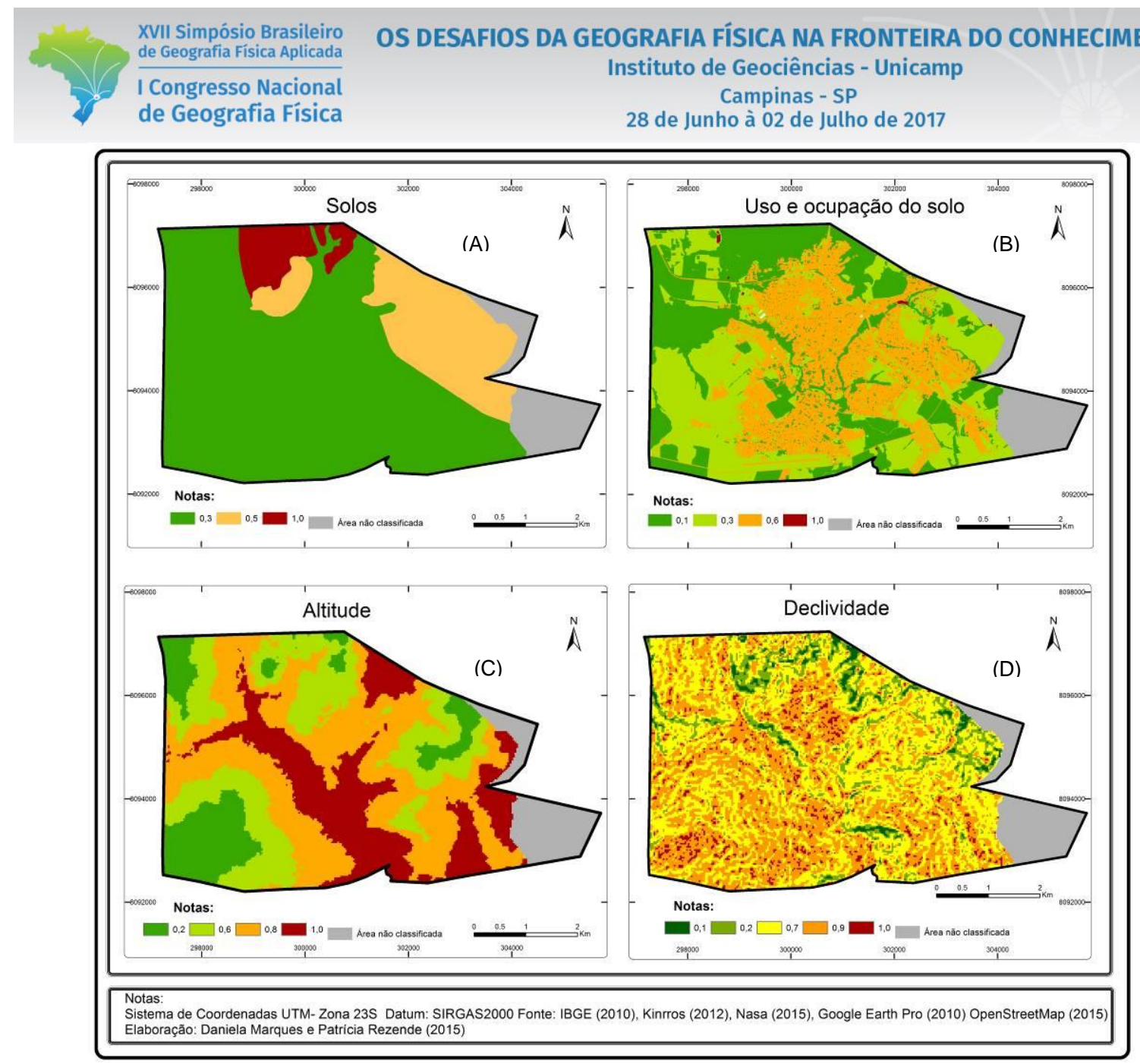

Figura 2 - Resultado da aplicação do modelo MRV

A partir dos resultados gerados, pode-se aplicar o método AHP, cujo plugin encontra-se disponível para ser instalado no software QGis.

\section{MÉTODOAHP}

A escolha do Processo Analítico Hierárquico - AHP está relacionada à necessidade de adotar métodos que auxiliem na tomada de decisões complexas. Desenvolvido na década de 1970, pelo Professor Thomas Saaty, na Escola Wharton da Universidade da Pensilvânia, esse método oferece a possibilidade de trabalhar considerações qualitativas e subjetivas, como é o caso das tomadas de decisões, combinadas com processamentos quantitativos (PINESE JÚNIOR, 2010 e AMARAL, 2006).

Uma vez delimitada a temática e selecionados os elementos a serem empregados no método, então é possível construir a Matriz de Comparação Pareada. Para isso, recorre-se a uma escala de pesos definida por Saaty (1977), seguindo a ordem de importância apresentada na Figura 3. 


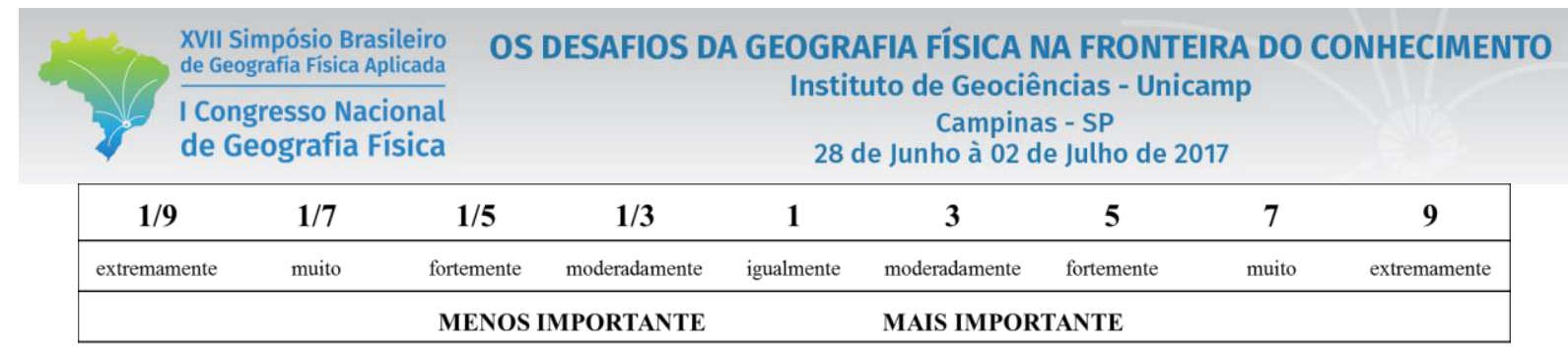

Figura 3 - Escala de comparadores com os respectivos pesos de importância Fonte: Adaptado de Saaty (1977)

De posse da escala de pesos (valores) para comparar as variáveis segundo seu grau de importância, constrói-se a matriz de comparação estabelecendo as importâncias mútuas. Essa é uma matriz quadrada e com valores recíprocos, sendo que na diagonal os valores são unitários, pois cada variável comparada a ela mesma é igual à unidade (SANTOS et al. 2010). Alguns exemplos de aplicação dessa metodologia podem ser vistos em Cerri e Paula (2012), Silva e Nunes (2009), Amaral (2006), dentre outros.

Em se tratando do estudo de riscos, foco deste trabalho, o método AHP ajudará na determinação do grau de importância das variáveis escolhidas através da comparação em pares, ou seja, classificando uma variável em relação à outra.

O método AHP, baseado na proposta apresentada por Saaty (1977) para definição da matriz de pesos, está disponível em diversos softwares de geotecnologias, como o QGis, usado neste estudo. Para operacionalização desse processo foi instalado o plugin Easy AHP na versão do QGis 2.8.1.

Os passos a serem seguidos para determinação dos pesos estatísticos executados no plugin Easy AHP são os seguintes:

(a) inserção das variáveis, por ordem de importância, sendo do menos para o mais importante;

(b) construção da Matriz de Comparação Pareada com inserção dos valores de interesse para o modelo, seguindo a escala de comparadores representada na figura 3. Após o cálculo da matriz, esse estágio ainda demanda a verificação de consistências dos resultados obtidos, conforme critérios estabelecidos por Saaty (1980 apud PINESE JÚNIOR, 2010). Essa averiguação, de acordo com Cerri e Paula (2012), é feita por meio do cálculo do Índice de Consistência (IC), da Razão de Consistência (RC) e do resultado apresentado em $\lambda$, os quais ajudam a verificar o resultado final da matriz.

Os resultados (Figura 4) encontrados para o IC (Índice de Consistência) foi de 0,041, valor este que deve estar o mais próximo de zero possível, a RC (Razão de Consistência), com 0,046 índice que precisa ser inferior a 0,10 e $\lambda$ com valor de 4,123, próximo do número de indicadores (4 variáveis), como recomendado na metodologia de Saaty (1977). 


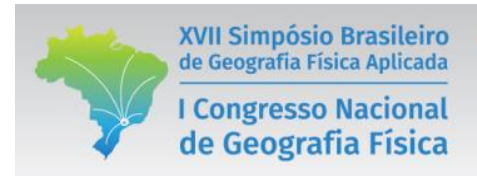
OS DESAFIOS DA GEOGRAFIA FÍSICA NA FRONTEIRA DO CONHECIMENTO
Instituto de Geociências - Unicamp
Campinas - SP
28 de Junho à 02 de Julho de 2017

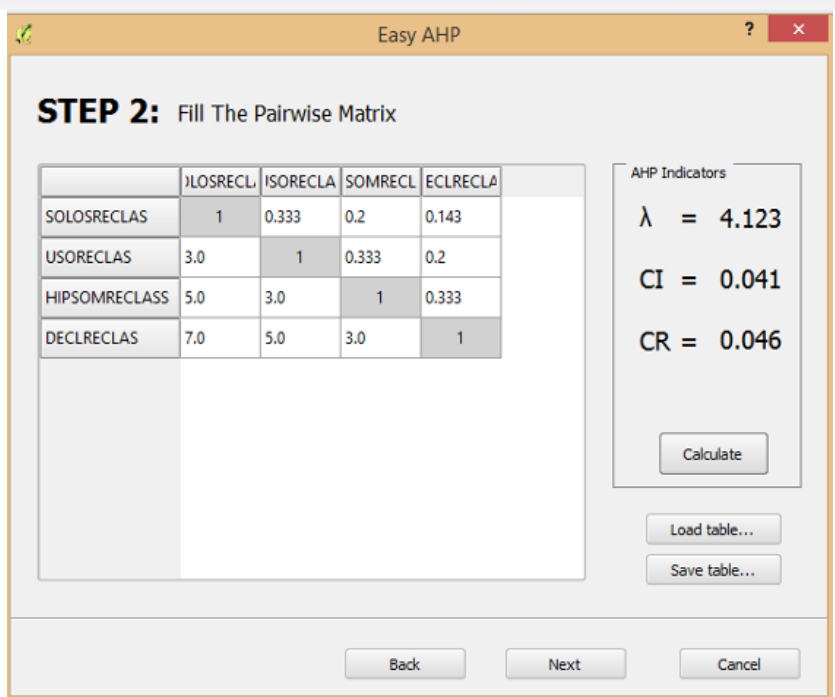

Figura 4 - Cálculo dos índices de consistência usando o plugin Easy AHP

(c) executada a matriz, tem-se os pesos estatísticos para cada variável (Tabela 2), os quais serão utilizados para a elaboração do mapa de risco a inundação pelo Weighted Linear Combination (WLC) integrado no plugin AHP.

Tabela 2 - Pesos das variáveis após aplicação da Matriz de Comparação Pareada

\begin{tabular}{cc}
\hline Variáveis & Peso \\
\hline Solo & 0,057 \\
Uso do Solo & 0,122 \\
Altitude & 0,264 \\
Declividade & 0,557 \\
\hline
\end{tabular}

(d) na etapa de análise com o WCL no plugin AHP, com base na importância de cada variável para o risco de inundação, é feito a multiplicação de cada variável pelo seu peso (Tabela 2) e soma-se os resultados (MALCZEWSKI, 2000), obtendo-se o mapa síntese final com valores variando na escala de 0 a 1 .

(e) por fim, ainda no Qgis, elaborou-se o layout, utilizando o produto final gerado no plugin Easy AHP em formato raster para análises, e uma visualização em 3D.

\section{Resultados e discussões}

No intuito de identificar e analisar as áreas susceptíveis a inundação, dividiu-se a área urbana de Paracatu em cinco classes quanto a esse risco, variando de muito baixo a muito alto, conforme o mapa da Figura 5. 

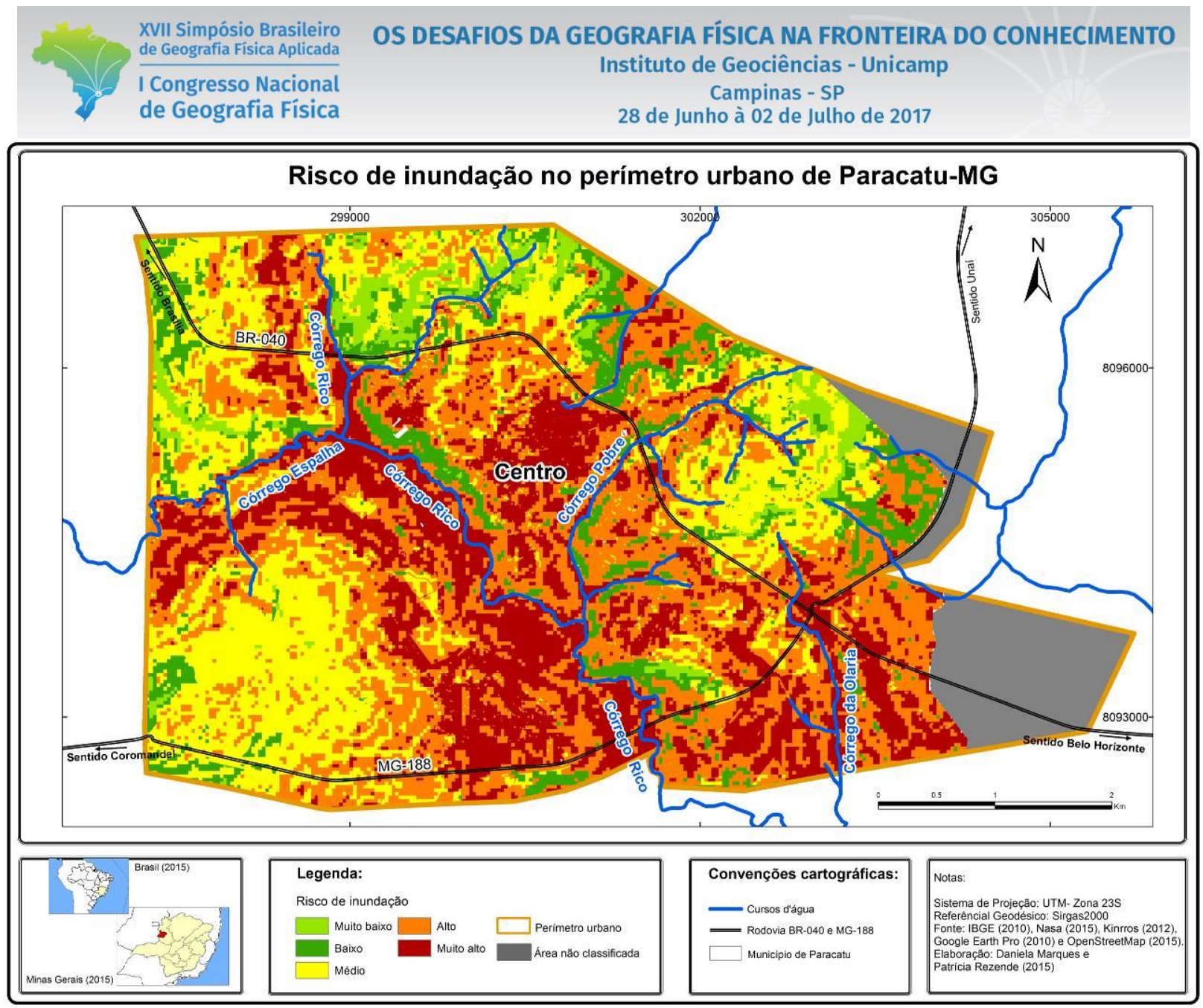

Figura 5 - Resultado do risco de inundação

O mapa demonstra que em $36 \%$ da área de estudo prevalece a classe alto risco de inundação, seguida pelas classes médio risco (26\%) e muito alto risco (25\%), representadas em tons laranja, amarelo e vermelho, respectivamente. As demais classes, exibidas em tons de verde, foram identificadas em poucas áreas na cidade, com percentuais de $9 \%$ para baixo risco e $4 \%$ para muito baixo risco.

Percebe-se que as áreas consideradas como de risco muito alto estão concentradas principalmente nas regiões mais baixas da cidade (altitude menor que 632m) e com declividades menores, inferiores a $2 \%$. Observa-se, ainda, que essa classe está localizada prioritariamente à margem direita do Córrego Rico, que, como já foi destacado, é o principal da cidade e recebe fluxo dos demais córregos.

Nessas áreas concentram-se edificações, as quais impedem que ocorra infiltração de água de chuva no solo. Com isso, toda água das enxurradas vai direto para o córrego. Apesar dessas áreas estarem localizadas majoritariamente em solos tipo latossolo, considerados bem drenados, percebe-se que a concentração de edificação nas proximidades dos córregos, associada à baixa declividade, intensificam o grau de risco a inundação, uma vez que a água tende a escoar com maior intensidade para o córrego, por falta de áreas permeáveis. 


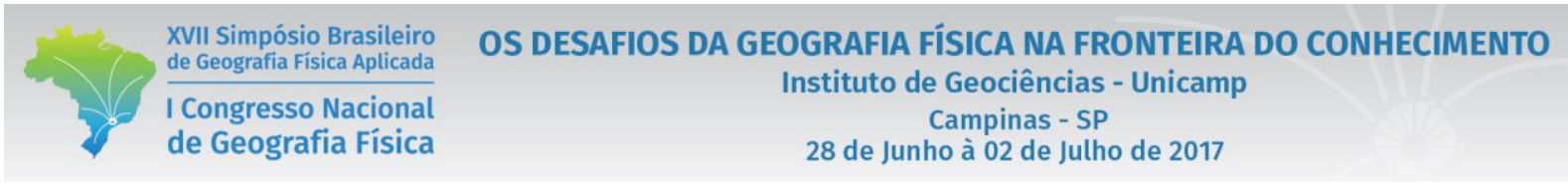

As áreas de risco alto também estão localizadas com maior frequência à margem direita do Córrego Rico. Entretanto, observa-se a existência dessa classe nas proximidades dos demais córregos e na parte central da cidade, onde se constatam declividades variando de 2 a $7 \%$ e áreas edificadas. A figura 6 apresenta um exemplo de moradia susceptível à ocorrência de risco a inundação devido a sua localização nas margens do córrego Rico.

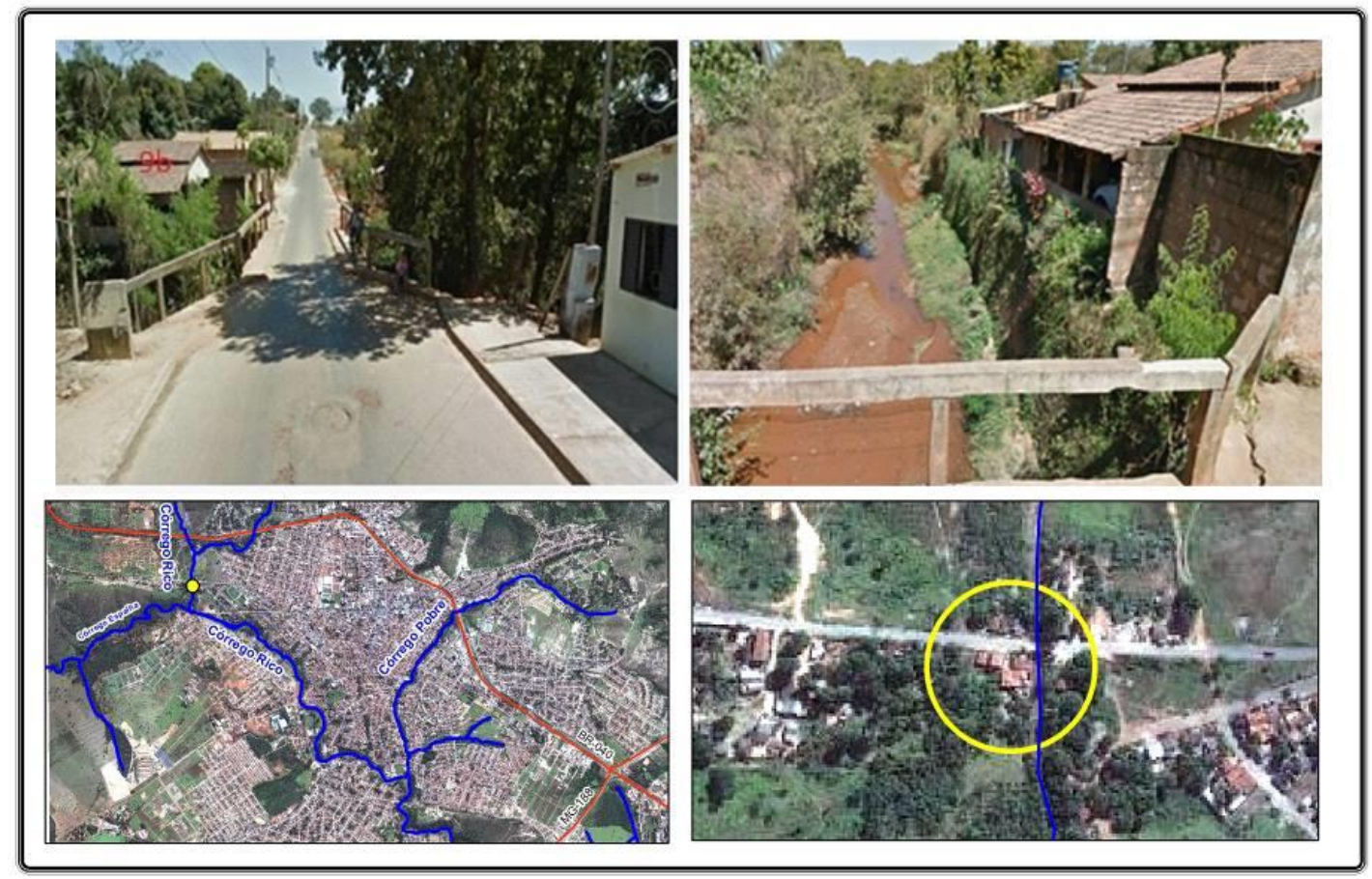

Figura 6 - Ocupações nas margens do Córrego Rico

Fonte: Google Earth (2010) e Google Street View (2014)

A classe de risco médio se concentra em espaços com declividades entre 7 e 15\%, altitude acima de 721 metros e com variação do tipo de solo, abarcando tanto, áreas de latossolos, quanto as de associação de cambissolos e neossolo. Contudo, o que se percebe é que a existência de área não edificada contribui para permeabilidade nesses locais, diminuindo assim a susceptibilidade à ocorrência de inundação.

A classe de baixo risco situa-se em áreas com declividades de 15 a 22\%, altitude acima de 766m, espaços não edificados e com cobertura vegetal. Essa classe está localizada principalmente em alguns pontos nas partes noroeste, norte, nordeste e sudoeste da zona urbana de Paracatu.

Por fim, a classe de risco muito baixo, que se localiza em áreas com declividades acima de $22 \%$, altitude acima de $800 \mathrm{~m}$, locais com alto percentual de cobertura vegetal e áreas não edificadas. Por apresentarem alto índice de permeabilidade e relevo ondulado, nessas áreas a possibilidade de haver inundação é inexistente. Entretanto, tais áreas podem se tornar geradoras potenciais de fluxo superficial, que é drenado 


\section{OS DESAFIOS DA GEOGRAFIA FÍSICA NA FRONTEIRA DO CONHECIMENTO \\ Instituto de Geociências - Unicamp \\ Campinas - SP \\ 28 de Junho à 02 de Julho de 2017}

para as partes baixas, fundos de vales, contribuindo, assim, para a ocorrência de inundações nesses locais, conforme pode ser visualizado na Figura 7.

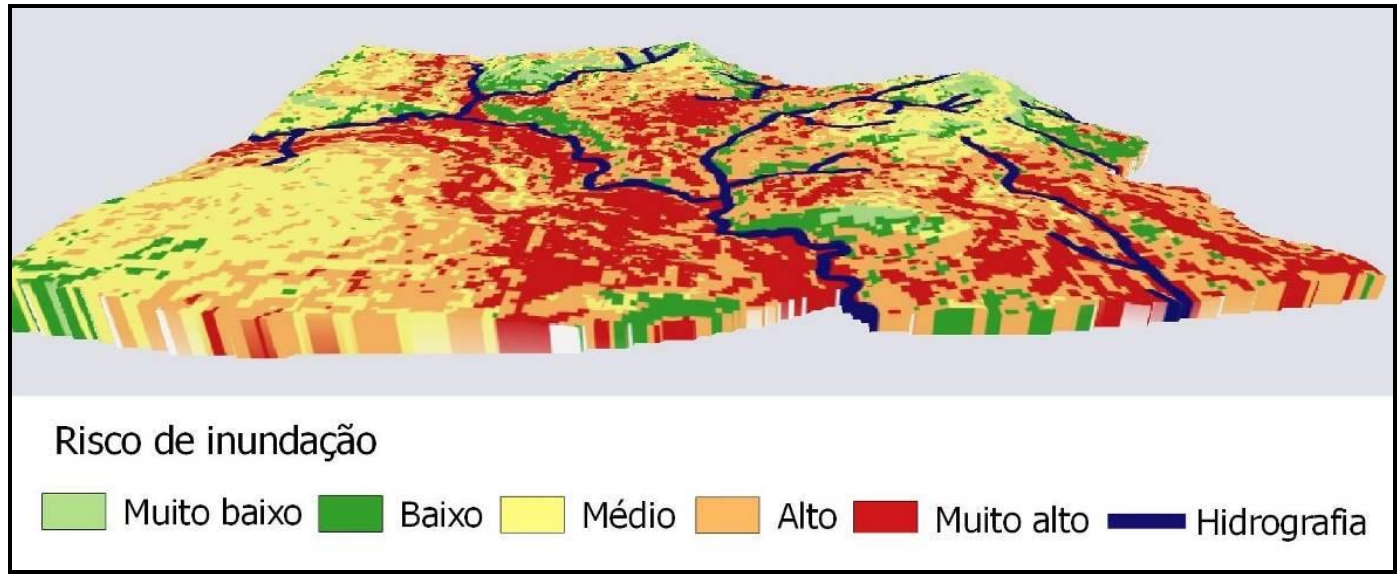

Figura 7 - Resultado do risco de inundação em 3D

Ao relacionar as informações do mapa de uso do solo com as do mapa de risco de inundação, ficou claro que o percentual de risco de inundação é mais alto nas áreas impermeáveis devido à presença de solos jovens, associados com a ocupação urbana. Assim, áreas impermeáveis contribuem também para o "aumento da velocidade e do volume de escoamento superficial das águas urbanas; aumento do número e da frequência das inundações; incremento da poluição difusa pela lavagem das superfícies urbanizadas (...)" (VARGAS, 1999 apud ANDRADE 2011, p.13). Sabendo desses impactos causados pela existência de áreas impermeáveis nas cidades, é necessário que os órgãos públicos criem estratégias e normas reguladoras para atenuar e compensar a impermeabilização dos solos.

\section{Considerações Finais}

A partir deste estudo foi possível identificar e analisar as áreas mais susceptíveis a ocorrência de inundação no perímetro urbano de Paracatu-MG. Para isso, aplicou-se a reclassificação de variáveis e o método de processo analítico hierárquico (AHP).

O uso de geotecnologias contribuiu de forma expressiva para as análises de risco à inundação, pois seus resultados auxiliarão os gestores na tomada de decisões de caráter mitigador, quando já tenha ocorrido a ocupação dos espaços inadequados, e preventivo, visando à qualidade socioambiental nas cidades.

No que diz respeito à utilização de um software livre para tratar a informação geográfica, como é o caso do QGis, cabe destacar que seu uso se mostrou muito adequado, ágil e útil na geração dos resultados finais expostos no presente estudo. Além disso, a existência de complementos a essa ferramenta, como o plugin 
Easy AHP, facilitou e deu agilidade ao processamento dos cálculos necessários para a análise multicritério, fornecendo resultados confiáveis.

Para futuros trabalhos, caso o pesquisador necessite de maior precisão das classes geradas, recomenda-se a inclusão de novas variáveis, tais como: morfometria da bacia, pontos de ocorrência de inundações, balanço hídrico, vazão e largura dos córregos.

Nos resultados alcançados foi constatado que as áreas de risco alto e muito alto estão localizadas na parte sul da cidade e apresentam como principais características urbanização acentuada, baixas declividades e relevo plano, sendo estes os principais fatores favoráveis a inundações.

Em contrapartida, as áreas consideradas como de risco baixo e muito baixo estão distribuídas onde predominam relevo ondulado, áreas permeáveis e vegetação, fatores esses que contribuem para que não ocorram inundações, além de garantirem uma qualidade ambiental em áreas urbanas.

Neste estudo, foi perceptível que o tipo de solo encontrado na área investigada não teve grande influência sobre o aumento da susceptibilidade à ocorrência de inundação. Por outro lado, o tipo de ocupação, declividade e altimetria contribuem de forma significativa para esse tipo de ocorrência.

Por fim, o desenvolvimento deste estudo gerou resultados capazes de mostrar claramente as áreas de risco a inundação e fornece subsídios a tomada de decisões por parte de gestores, profíssionais da área e pesquisadores/estudantes.

\section{Agradecimentos}

Os autores agradecem a CAPES e à Embrapa pelo apoio no desenvolvimento do curso de Doutorado.

\section{Bibliografia}

AMARAL, J. F. S. Aplicação do processo analítico hierárquico como suporte à decisão na produção bovina d e corte na região de Betim/MG. Belo Horizonte, Universidade Fumec, Faculdade de Ciências Empresariais, 2006. (Dissertação de Mestrado)

ANDRADE, S.L. Elaboração de um mapa de risco de inundações da bacia hidrográfica do Córrego São Pedro, área urbana de Uberlândia- MG. Uberlândia, Universidade Federal de Uberlândia, 2011.(Monografia)

CÂMARA, G. e MEDEIROS, J. S. Modelagem de dados em geoprocessamento. In: (org.) 2 ed.

Geoprocessamento para projetos ambientais. São José dos Campos: INPE, 1998. p. 1-35. 
CERRI, L. E. S. e PAULA, B. L. Aplicação do processo analítico hierárquico (AHP) para priorização de obras de intervenção em áreas e setores de risco geológico nos municípios de Itapecerica da Serra e Suzano (SP). São Paulo: UNESP, Geociências, v. 31, n. 2, 2012, p. 247-257.

ESTEVES, C. J. O. Risco e Vulnerabilidade Socioambiental: aspectos conceituais. Cad. IPARDES, Curitiba-PR. V1, n2, p.69-79, 2011.

IBGE. Instituto Brasileiro de Geografia e Estatística. Cidades IBGE. Disponível em <

http://cidades.ibge.gov.br/xtras/perfil.php?codmun=314700> Acesso em: 20 de julho de 2014 .

IBGE. Instituto Brasileiro de Geografica e Estatística. 2010. Bases cartográficas: malhas digitais. Disponível em: $<$ http://mapas.ibge.gov.br/bases-e-referenciais/bases-cartograficas/malhas-digitais.html>. Acesso em: 22 de out. 2015.

MAGALHÃES, I. A. L.; THIAGO, C. R. L.; AGRIZZI, D. V.; SANTOS, A. R. Uso de geotecnologias para mapeamento de áreas de risco de inundação em Guaçuí, ES: uma análise comparativa entre dois métodos. Cadernos de Geociências, v. 8, n. 2, nov. 2011, p. 63-70. Disponível em:

<http://www.portalseer.ufba.br/index.php/cadgeoc/article/viewFile/5288/4036> Acesso em: 27 mai. 15.

MAGALHÃES, I. A. L.; AGRIZZI, D. V.; THIAGO, C. R. L.; SANTOS, A. R. Metodologias distintas para mapeamento das áreas de risco de inundação em Guaçuí, ES, utilizando sistemas de informações geográficas. In: SANTOS, A. R.; PELUZIO, J. B. E.; PELUZIO, T. M. O.; SANTOS, G. M. A. D. A. (org.) Geotecnologias aplicadas aos recursos florestais. Alegre - ES, 2012. p. $114-125$.

MALCZEWSKI, J. On the Use of Weighted Linear Combination Method in GIS: Common and Best Practice Approaches. Transactions in GIS, v. 4, n. 1, 2000, p. 5-22.

MENDONÇA, F. A; LEITÃO, S. A. M. Risco e vulnerabilidade socioambiental urbana: uma perspectiva a partir dos recursos hídricos. GeoTextos, vol. 4, n. 1 e 2, 2008, p. 145-163.

Nasa, USGS. Department of the Interior U.S. Geological Survey. Disponível em: <http://earthexplorer.usgs.gov> Acesso em: 03 maio de 2015.

PINESE JÚNIOR, J. F. Aplicação do método de análise hierárquica - AHP - para a determinação da vulnerabilidade ambiental da bacia hidrográfica do Rio Piedade, MG. Uberlândia: UFU, 2010. (Monografia)

QGIS. User Guide - Version 2.8.1. 2015. Disponível em: < http://www.qgis.org/en/site/> Acesso em 02 de jun. 2015.

SANTOS, A. R.; LOUZADA, F. L. R. O.; EUGENIO, F. C. ARCGIS 9.3 total: aplicações para dados espaciais. Alegre, ES: CAUFES, 2010. 184 p. 


\begin{tabular}{|c|c|}
\hline $\begin{array}{l}\text { XVII Simpósio Brasileiro } \\
\text { de Geografia Fisica Aplicada } \\
\end{array}$ & $\begin{array}{l}\text { OS DESAFIOS DA GEOGRAFIA FÍSICA NA FRONTEIRA DO CONHECIMENTO } \\
\text { Instituto de Geociências - Unicamp }\end{array}$ \\
\hline $\begin{array}{l}\text { I Congresso Nacional } \\
\text { de Geografia Física }\end{array}$ & $\begin{array}{l}\text { Campinas - SP } \\
28 \text { de Junho à } 02 \text { de Julho de } 2017\end{array}$ \\
\hline
\end{tabular}

SAATY, T. H. A scaling method form priorities in hierarquical structures. Journal of Mathematical Psychology, v.15, n. 3, p. 234-281, 1977.

SILVA, C. A. e NUNES, F. P. Mapeamento de vulnerabilidade ambiental utilizando o método AHP: uma análise integrada para suporte à decisão no município de Pacoti/CE. In: XIV SIMPÓSIO BRASILEIRO DE

SENSORIAMENTO REMOTO, 14. 2009, Natal. Anais... Natal, INPE, 2009. p. 5435-5442. 